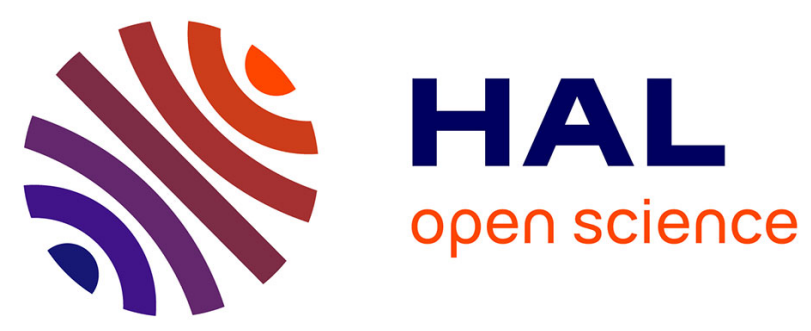

\title{
How Interactives Can Change Learnability of Science Concepts for Young Children - Re-positioning Them as Learners 'Who Can and Did'
}

Cheryl Jakab, Christine Redman

\section{- To cite this version:}

Cheryl Jakab, Christine Redman. How Interactives Can Change Learnability of Science Concepts for Young Children - Re-positioning Them as Learners 'Who Can and Did'. 11th IFIP World Conference on Computers in Education (WCCE), Jul 2017, Dublin, Ireland. pp.292-303, 10.1007/978-3-31974310-3_31. hal-01762908

\section{HAL Id: hal-01762908 \\ https://hal.inria.fr/hal-01762908}

Submitted on 10 Apr 2018

HAL is a multi-disciplinary open access archive for the deposit and dissemination of scientific research documents, whether they are published or not. The documents may come from teaching and research institutions in France or abroad, or from public or private research centers.
L'archive ouverte pluridisciplinaire HAL, est destinée au dépôt et à la diffusion de documents scientifiques de niveau recherche, publiés ou non, émanant des établissements d'enseignement et de recherche français ou étrangers, des laboratoires publics ou privés.

\section{(c)(1)}

Distributed under a Creative Commons Attribution| 4.0 International License 


\title{
How Interactives can Change Learnability of Science Concepts for Young Children - Re-Positioning them as Learners 'who Can and Did'
}

\author{
Cheryl Jakab and Christine Redman \\ Melbourne Graduate School of Education, The University of Melbourne, Australia \\ cjakab@unimelb.edu.au ${ }^{1}$ redmanc@unimelb.edu. $a u^{2}$
}

\begin{abstract}
This paper explores what young children can and will 'say and do' when positively positioned to think with scientific concepts using ICT interactives. The progress with meaning-making of three young children (7, 9 and 12 years old) when playing a game is tracked and analysed. How these children were positively positioned with the concepts and what this afforded them in the setting are outlined. Analysis of their 'sayings and doings', using affordances and positioning theory, details their progress in meaning-making with the offered chemistry concepts. What each child did with the three levels of thinking of chemistry (macro/submicro/symbolic), was tracked.. Three chemical thinking storylines are described to highlight that exploring molecular and chemical symbolic thinking can lead young children to engage with more scientifically sophisticated thinking and is of interest to them. Many scientifically relevant questions were raised while 'playing' with the interactive. The game directed their attention to the chemistry concepts and led to meaning-making opportunities. This examination provides insights into how suitable interactives can offer, direct and help structure early 'knowing of' scientific concepts by positively positioning learners with the concepts. Implications for restructuring early learning opportunities with central concepts using ICT are proposed.
\end{abstract}

Keywords. Interactives, early learning, positive positioning, science concepts

\section{Introduction}

Using 21st century ICT tools is changing possibilities in learning and teaching [1]. Many ideas that are difficult to explain using words alone become more readily interpreted and understandable when re-presented in diagrams, images, video and computer-generated imagery (CGI) combinations. They say a picture is worth a thousand words. What worth then, of today's interactives, simulations and visualizations? Making sense of many previously considered difficult concepts is made easier through today's multimodal offerings. Noss goes further in his research, showing available visualization and simulation tools afford [2] new 'learnabilities' and 'teachabilites' for all, for scientists, adults and children alike.

The wealth of innovative interactive ICT resources available today includes many child-friendly educational interactive games, models, images and simulations.

The vast majority of the research into the use/s of ICT simulations and visualizations to support science learning have been conducted at secondary and 
tertiary levels [3]. The majority of the research focus is on "soft skills", that is, the uses of ICT as communication tools, for developing communities of learners, CoL [3] and for representing and modelling [4].

In science curriculum designs, young children are routinely introduced to chemistry through the sensory level of substances in their primary (elementary) schooling [5]. The particulate nature of matter or molecular thinking and chemical symbols are then included into chemistry in secondary schooling [6].Thus the introduction to chemical science begins with macro-only activities involving exploration of physical and chemical changes, delaying the introduction of molecular and symbolic levels of chemical thinking until middle years or even late secondary years. It is argued this is due to the 'abstract' nature of the concepts [5, 6]. After decades of this approach, expressed in the literature are problems of conceptual load, 'difficulty' and lack of engagement with chemistry. These problems remain of great concern. The numerous difficulties learners experience with the three levels of chemical thinking (Fig.1) have been well documented, over many decades.

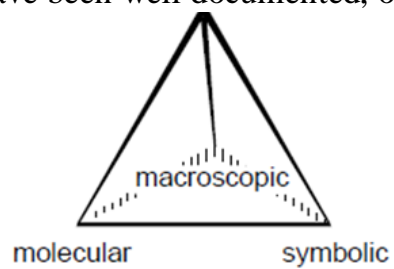

Figure 1. Three levels of chemical thinking

As Skamp concludes in his review of the arguments, whether to teach particle ideas in primary science is still in debate.

The majority of research into ICT use in science learning is concentrated at secondary and tertiary levels. Using ICT can clearly support successful learning in science and other fields. We theorise that current visualisation tools can and will change developmental learning trajectories, that is, not only how we learn but what we can learn and when. Underpinning our research is the belief that the re-evaluation of how we view concepts, away from being accepted as abstract [7] in and of themselves, towards acknowledging that learning of any concept is contingent on the material and social supports that position a learner in a learning opportunity. We are interested in revisiting the early exploration of complex science concepts, the 'big ideas', with children today, using currently available multimedia and visualisation resources. We believe these could engage learners with new ways of seeing and doing and provide effective scientific-thinking learning opportunities that can better spark curiosity and motivation towards learning in sciences [8].

In this work, we explore a little described use of ICT in the 'new cultures of learning' for the initial offering of the three levels of chemical thinking to young children. The present study stems from a broader doctoral study conducted by author one and supervised by author 2 that was prompted by a long term interest in how science resources interact with and direct what children can know and do [9] and under what circumstances. Here we explore what happens when young children were offered particle of matter concepts in an interactive game that is specifically designed for young children to use [10]. We present the offering of concepts as re-positioning 
the learner with the concepts using Positioning Theory [11] to underpin the research design, conduct and analysis. Here we explore children making meaning with particle concepts, atoms and molecules, showing how they progress, when the conceptual tool [12] is made available for thinking with. What do young children do and say when positively (re-) positioned with ideas about particles of matter, one of the biggest 'big ideas' of science?

The major objectives of this paper are to:

- describe how material and social supports can be provided to positively (re-) position young children for initial 'knowing of' concepts of atoms and molecules using ICT; and

- highlight the engagement and scientific sophistication of young children's 'doings and sayings' when they are positively positioned with chemical concepts in suitable ICT interactives.

\section{Methodology and Analysis}

This paper is based on data collected in a broader doctoral study (HEAG 183/09 Ethics ID: 0828473) involving 24 self-selected volunteers, who were from one state primary school, located in central Victoria, Australia [13]. A sociocultural approach to the methodology was taken, acknowledging that the material and the social contexts that a child finds themselves in, constrains and enables particular learning trajectories. What learners are afforded, what they can and will do in meaningmaking, is taken as contingent on circumstances. Sociocultural approaches add to the study of learning by seeing self-systems and social systems as mutually constitutive [14].

The methods of discursive psychology provided the answer to how to research meaning-making in social action [15]. Positioning Theory was employed to focus on the dynamic positions, acts and storylines enacted in the study interviews. Positioning Theory supports consideration and examination of how people take up positions and negotiate their identity in conversations and actions. The enactment of positions in a conversation is expressed in both speech acts and bodily actions. Positions emerged naturally in the research conversations between the interviewees and the interviewer while exploring the interactive Molecularium building games [10]. Storylines are extended interactions on a topic, that can often be revisited throughout an interview. Positions emerge in conversations and other social episodes, including conversational interviews. Storylines are returns to themes in sequences of acts/actions. Many storylines can be identified in any sequence of interactions. Using positioning theory encourages researchers to be aware, at all times, of the constant changes in positioning and (re-) positioning of the participants throughout interactions. In this paper, with its focus on chemical learning using ICT, the emergence of chemical storylines in the interview interactions are highlighted.

\subsection{The research interviews}

One-on-one conversational interviews were designed and conducted to explore the progress of individual children in using 'molecular thinking'. 
The interviews were held in a neutral space familiar to the participants at a mutually agreed time. Each young participant was invited into being a knowing coresearcher, including choosing their study code name and having the research purpose explained.

The double stimulus conversational one-on-one interview form was designed for the doctoral research mentioned above and was audio and video recorded. The first stimulus invited the participants to interact with a wide range of representations of molecules and atoms. This began with establishing their existing everyday (intramental) knowledge by asking them 'What do you think of...?' when asked if they could read the word 'molecule' and then 'atom', They were then shown chemical images and formulae to discern if any were familiar from everyday life. The final step of this stimulus 1 step, which is the focus of the reporting in this paper, was designed to explore what they 'did and said' with the material assistance of 'playing' the interactive molecule 'Build' game on the Molecularium website [10]. (The second stimulus of the interview which is not reported on here, asked participants to use 'molecular thinking' to explain a macro level physical change, a commonly used starting point in early school chemistry.)

Every effort was made to maintain the research interview as an everyday conversation, applying positioning theory in the design and conduct of the interviews, as well as in the analysis of the interview conversations. This enabling interview involved ongoing and close attention by the interviewer to the child's doings and sayings in the context, with social supports aimed at keeping the experience as naturally conversational as possible, while maintaining focus on the researcher's project of chemistry meaning-making. Inter-mental activity was acknowledged as necessarily part of the interview process, with any natural teaching scaffolds forming part of the interactions. This interview design opens for research what the children could, will and do 'say and do' and under what circumstances [9, 16]

The three participants selected to report on in this paper demonstrated different levels of 'everyday' knowledge about atoms and molecules at the starting point of the study. The three also showed contrasting approaches to the interactive game. These three are referred to throughout by their self-selected code names, Mr. No-one, Zia and Robert. (We note here that the participant Mr. No-one was asked if Mr. N could be used instead, however he refused. We respect that decision here and use his chosen code name).

The youngest, seven year old Mr. No-one was still a beginning reader and could activate no prior knowledge of molecules or atoms when shown words and related images at the start of the interview; Nine year old Zia stated "small particles" when asked and Robert (11.9 years) had very high level everyday knowledge. Robert expressed great extant interest in/about the particulate nature of matter, giving an immediate accurate definition as a sentence 'molecules are made up of atoms'.

The combined individual child-material support-social setting is the target research object. This is in contrast to research aimed at finding out what children currently know or can do relying solely on their own mental resources. This research targets what they can do with the ideas when positioned with material and social supports. The material support came in the form of a freely available interactive online molecule building game found at the Molecularium Kidsite Nanolab that is designed for use by young children The format of the game offers players opportunity to 
interact with numerous examples of chemical concepts at all three levels of chemical thinking, that is, the molecular, symbolic and macroscopic. The chemical conceptual categories of molecules and atoms, and their interrelationships, based on the proposition that 'molecules are built from atoms', are instantiated in the playing.

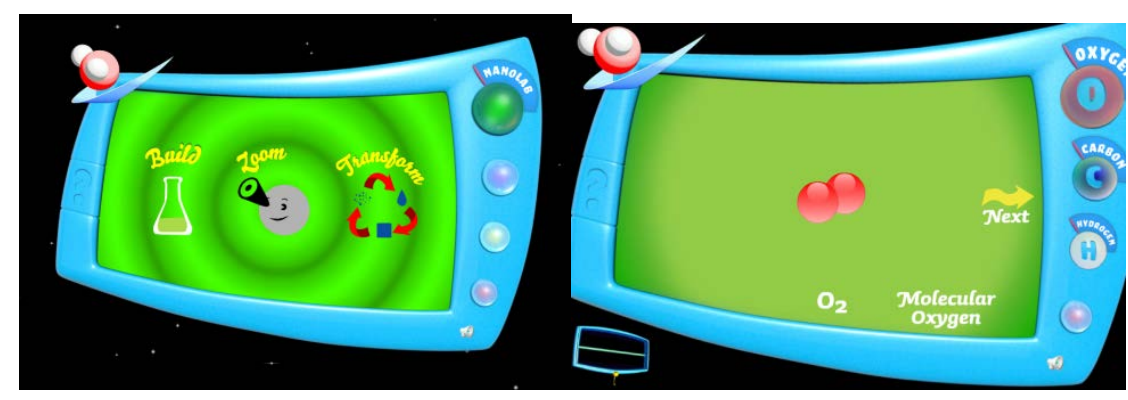

Fig 2 Molecularium Kidsite Nanolab screen and example $\mathrm{O}_{2}$

Using the Molecularium game players build a number of different molecules, offered in chemical symbol prompts, Players use three kinds of atoms, hydrogen, carbon and oxygen, to build molecules. This begins with $\mathrm{O}_{2}$ and molecules get larger and larger, including methane and sugar $\mathrm{C}_{6} \mathrm{H}_{12} \mathrm{O}_{6}$. After a successful 'build' of a molecule, macrolevel information about the substance built is provided by the game voice over. Thus, playing opens an initial experience for the 'knowing of' differentiated chemical concepts, that is, knowing about a range of substances at the molecular, symbolic and macro levels. The social other in this research is the interviewer, who scaffolded this experience by positively positioning the interviewee, in the setting. Interaction choices and turn taking maintain the conversation as natural and support concept learning in the conversation. The child's own interests and projects were respected and supported while assisting a focus on chemical thinking throughout.

\subsection{Analysis}

The analysis, highlighting affordances and using positioning theory, isolated a number of chemical thinking storylines that were pursued in the conversations, as the participants interacted with the game with the social support of the more expert other [12]. The participant's positioning and re-positioning shown in the 'doings and sayings' and their dispositions while playing with the interactive are the focus [6]. The interplay between the meaning-making with the tools at hand and the social supports that were needed moment-to-moment, identify the individual ways the participants progressed with the concepts in the game and the specific chemical storylines they focused on at various times.

A brief summary of the 'doings and saying' in molecule building activity for the three very different young co-researchers, Mr.-No-one, Zia, Robert, is presented in Table 1 . The analysis summary in Table 1 shows the approach to the game by Mr. No-one, Zia and Robert varied greatly. 
Table 1. Summary of three students exploring the Molecularium

\begin{tabular}{|c|c|c|c|}
\hline $\begin{array}{l}\text { Molecule } \\
\text { to build }\end{array}$ & $\begin{array}{l}\text { Mr. No-one (7yo) } \\
\text { (Very low starting } \\
\text { knowledge) }\end{array}$ & $\begin{array}{l}\text { Zia (9yo) } \\
\text { (Typical medium } \\
\text { starting knowledge) }\end{array}$ & $\begin{array}{l}\text { Robert (11yo) } \\
\text { (Very high starting } \\
\text { knowledge) }\end{array}$ \\
\hline $\mathrm{O}_{2}$ & $\begin{array}{l}\text { Took control of } \\
\text { mouse without } \\
\text { hesitation, made } \\
\text { several mistakes, } \\
\text { retries - great } \\
\text { willingness to } \\
\text { explore as a game } \\
\text { by trial and error. } \\
\text { "This is fun". }\end{array}$ & $\begin{array}{l}\text { "What do we have to } \\
\text { do?” shared ideas } \\
\text { openly in talk - read } \\
\mathrm{O}_{2} \text { and reinterpreted } \\
\text { as } \mathrm{H}_{2} \mathrm{O} \text { initially, } \\
\text { aware of oxygen as } \\
\text { word for a gas -the } \\
\text { symbol unfamiliar }\end{array}$ & $\begin{array}{l}\text { Immediate control of } \\
\text { mouse and click on O } \\
\text { saying out loud towards } \\
\text { the computer (not to } \\
\text { researcher social other) } \\
\text { oxygen 'one atom'. } \\
\text { Immediate 'reading' of } \\
\text { subscript } 2 \text { as doubt, } \\
\text { understood as a problem } \\
\text { and rapid decoding with } \\
\text { the game tool. }\end{array}$ \\
\hline $\mathrm{H}_{2} \mathrm{O}$ & $\begin{array}{l}\text { Still in control of } \\
\text { mouse but makes } \\
\text { several mistakes, } \\
\text { retries and } \\
\text { willingness to } \\
\text { explore as a game - } \\
\text { water named out } \\
\text { loud as familiar. "I } \\
\text { know ..." }\end{array}$ & $\begin{array}{l}\text { "I know because ... so } \\
\text { now I understand it" } \\
\text { "that's what I drew" } \\
\text { "I made water" } \\
\text { "Water is two } \\
\text { hydrogen and one } \\
\text { oxygen” This is fun! } \\
\text { Really, really weird - } \\
\text { one more is hydrogen } \\
\text { peroxide. }\end{array}$ & $\begin{array}{l}\text { Immediate build } \\
\text { without support now } \\
\text { subscript as known, } \\
\text { next build } \mathrm{H}_{2} \mathrm{O}_{2}- \\
\text { symbol recognised as } \\
\text { not seen before. "I } \\
\text { Know..." Heard of } \\
\text { hydrogen peroxide once } \\
\text { the name was sounded } \\
\text { by the game. }\end{array}$ \\
\hline $\begin{array}{l}\mathrm{CH}_{4} \text { and } \\
\text { other } \\
\text { CHO's }\end{array}$ & $\begin{array}{l}\text { Self talk-thinking } \\
\text { out loud, "what } \\
\text { could?” } \\
\text { Effortful in any } \\
\text { reading symbol, } \\
\text { "What is that?” "Oh } \\
\text { yes - gas" }\end{array}$ & $\begin{array}{l}\text { What is hydrogen? } \\
\text { "This is pretty easy!" } \\
\text { Reading subscripts } \\
\text { accurately }\end{array}$ & $\begin{array}{l}\text { The space fill molecule } \\
\text { rather than stick and } \\
\text { ball basis of discussion } \\
\text { "The sticks good when } \\
\text { want to see how they } \\
\text { are joined" } \\
\text { "I like the way they } \\
\text { move around to show } \\
\text { the angles" }\end{array}$ \\
\hline Sucrose & $\begin{array}{l}\text { Did not get to this } \\
\text { level }\end{array}$ & $\begin{array}{l}\text { Counted numbers of } \\
\text { carbons- discussed } \\
\text { size of molecule }\end{array}$ & $\begin{array}{l}\text { Opinions of benefits of } \\
\text { space fill and ball \& } \\
\text { sticks in models }\end{array}$ \\
\hline
\end{tabular}

\section{Findings}

Mr. No-one, the youngest of the three participants expressed no prior knowledge, was willing to use trial-and-error from the start, showing experience with such games. He took control of the mouse and made several mistakes. He was very willing to try and try again. In contrast, Zia asked for support with "What do we have to do?" The position Zia had taken is reflected in use of "we", showing she chose to share her problem of how to start. Robert, similar to Mr. No-one, was also ready to begin independently, willingly taking control of the computer mouse and starting to click on icons. Playing the game rapidly became their bodily focus, and in doing their clicks on $\mathrm{H}, \mathrm{C}$ and $\mathrm{O}$ icons provided entry into thinking with and about particle concepts. 
Playing the game provided new words and images representing concepts. These new items of attention engaged their active interest 'in the doing' with the game.

The 'doings' showed the game aroused interest in, and competence with, the tasks of molecule building. The game directed the process in a step-by-step offering of more and more complex molecules to build. The immediate feedback from the game on success, or lack of success, encouraged each learner, in their own way, to focus efforts on the task of building the molecule shown as a chemical formula. Getting immediate feedback about whether they had pressed the right icon. A C (carbon), $\mathrm{H}$ (hydrogen) or O (oxygen) for atom kinds, the three participants each gained a number of experiences with examples. These incorporated the three levels of chemical thinking and introduced the meanings of chemical symbols as intended in chemistry. Re-positioning the participants with this interactive ICT game, along with suitable social scaffolding of their activity, provided individualised learning opportunity and appropriation of the offered concepts that are routinely accepted (in the much of the literature and curriculum designs) as too abstract for young children to use and learn. Each 'build' offered opportunity to 'read' (scientifically correct) chemical symbols. Incorrect clicks led to a 'start again' feedback, reinforcing that there is a right answer to the problem presented. The decoding of a number of instances of chemical formulae was linked in the game, through making clicks on icons, to a specific number of different kinds of atoms. Players thus create and observe accurate $3 \mathrm{~d}$ images of molecules on the screen. Each molecule 'build' gave practice with three levels of thinking, with precise form and structure (as a space fill model that moved around to show it has shape), and at the same time the uses and properties of a macro world substance (e.g. water). The provision of verbal macro level information at the end of the 'build' connected the symbols and molecules to sensory level information. All three participants described here, kept their focus directed on building without any need for social prompting from the interviewer/researcher to do so. The game was of interest and motivated the participants to raise chemically sophisticated questions about atoms, molecules, their symbols and sensory level macro world substances. The following section describes some of the ways meaning-making progressed with the specific chemical thinking tool for these three positively positioned participants, each in their own way. The analysis summarised in Table 1 highlights that the game engaged all three in doing with the concepts offered by the game and in this setting. Molecules with a small number of atoms $\left(\mathrm{O}_{2}, \mathrm{H}_{2} \mathrm{O}, \mathrm{CO}_{2}, \mathrm{CH}_{4}\right)$ were successfully built by all participants and larger sugar molecules by Zia and Robert (and the majority in the broader study). Mr. No-one and Zia were unwilling to say or 'taste the words' molecule and atom 'in the mouth' early on when asking questions, while Robert voiced the words readily.

Robert quickly progressed through all levels of the game, going on to extras including $\mathrm{C}_{60}$. Zia began to say the words atom and molecule first quietly to herself and then more openly out loud after three builds. Mr. No-one in the same length of game playing time built only five molecules. All three showed they were equally engaged with the game, talking as they played by trial and error, and finally coming to be able to independently accurately decode the chemical signs. Each began to use the words molecule and atom and expressed great achievement when the game and ideas made sense for them. 


\subsection{Emerging Storylines}

The participants' interactions with the game led to a wide range of scientifically relevant storylines emerging. Three storylines presented here highlight the entry positions and the effortful re-positionings these children experienced in using knowledge of particles concepts. The initial 'knowing of' the categories and kinds of these entities and the subsequent practice in using the metaphor of building molecules from atoms, directed participants to explore the scientific concepts and constrain their understanding towards the scientific. The selected samples of storylines below give some insights into the ways chemical meaning-making with the offered concepts progressed.

\section{Storyline \# 1 Reading chemical subscripts}

At the first build, how to make the $\mathrm{O}_{2}$ using clicks on buttons presented a problem for all participants. The ' $\mathrm{O}$ two' heard in the game voice over, was familiar. However, the numbers in the offered chemical formula, the two in $\mathrm{O}_{2}$, which in chemistry stand for two of those atoms in the make up the molecule, were not immediately interpreted. When no number '2' was available as a button, all participants hesitated. The iconic nature of the sign meant the meaning of subscripts had not previously been considered as needing decoding by Mr. No-one, Zia or Robert (nor any participant in the broader study). The realization of a problem that an alternative to a 'two' was needed, gained a swift, appropriate response from Robert, (and others in the higher everyday knowledge group). Robert's swift resolution of his problem allowed his rapid progress, quickly moving through decoding further chemical formulae by applying the knowledge he gained when building $\mathrm{O}_{2}$ and then $\mathrm{H}_{2} \mathrm{O}$. Mr. No-one showed he wanted to solve his problem by himself using trial and error, and did so, though slowly. Zia was least willing of the three to 'give it a go', needing encouragement by the social other to act. The prompt: 'what might the 2 be standing for?' led to a slow but correct action. All participants resolved the chemical subscripts problem during the playing and were conscious of having done so: as Zia actually stated when building methane "This is pretty easy!"

\section{Storyline \# 2 I know .... $\mathrm{H}_{2} \mathrm{O}$}

The whole sign, $\mathrm{H}_{2} \mathrm{O}$ meant water for No-N, Zia and Robert, and indeed for all participants in the broader doctoral study. The chemical symbols were familiar from everyday life. The expression of 'I know' showed a connection between the symbols and the participants everyday life. Each expressed some interest in knowing more and raised questions about the symbols. The specific interpretive problem that the participants experienced with the chemical formulae signs early in the game indicated they were reading chemical symbols as iconic signs (e.g. $\mathrm{H}_{2} \mathrm{O}=$ water) rather than reading them as intended in chemistry. The iconic signs recognized from everyday life, expressed as 'I know..." changed to be more scientifically meaningful chemical symbols that were open to decoding in playing with the interactive game. The game offered the opening to scientific information that chemical symbols represent atoms and molecules in a meaningful and knowable way. 


\section{Storyline \# 3 This is ... fun/interesting/easy}

The three participants each expressed in words and their actions, engagement with the game, particularly their satisfaction with progress in the use of the signs. The molecular formulae, including O2, $\mathrm{H} 2 \mathrm{O}, \mathrm{CH} 4$ were decoded. This provided practice in the idea that the letter represents a type of atom and the numbers the number of that atom in a molecule. This meaning and meaning-making experience was described positively as fun/interesting/ easy/ amazing. The representation of the built molecules as $3 \mathrm{~d}$ objects on a screen was identified as new and very helpful to developing thinking about molecules. Robert expressed his own position of valuing, offering: "I like the way they move around to show the angles.” By the third 'build' Zia's clicks on the screen buttons had become very fast, her decoding of the chemical symbols for molecules as clicks, was performed without doubt or hesitation. Indeed, in starting to build larger molecules containing $\mathrm{H}, \mathrm{C}$ and $\mathrm{O}$ atoms she stated, in her self talk: "This is pretty easy!" while almost simultaneously asking out loud the scientifically relevant question: "What is hydrogen?". Mr. No-one was excited by successes. As a poor reader, but a willing learner in trial and error visual games, his progress was expressed in words as well as affect as "exciting".

\section{Conclusions}

The purpose of this project was to better understand how to position learners with contemporary technologies to open and support conceptual learning. This paper reports on what happened when young children were positively positioned with a digital game that is designed to introduce young children to scientific ideas of molecules and atoms and their chemical symbols. In the analysis the three young participants, each with a very different starting point knowledge, were motivated by a process of 'seeing what might be' that inspired them to move forward and explore the offered concepts with a sense of anticipation in the interactive molecule building game. While the three students are very different from each other, all three showed interest in the game's concepts, asked scientifically sophisticated questions about the chemical ideas offered and gained knowledge about these ideas in playing. They each stated at the end of their interview they would like to learn more about atoms and molecules and thought they should do so around eight years of age.

We take the main benefit of the game is that it offered the children all three levels of chemistry representation to use together as tools for their thinking. The participants raised scientifically appropriate questions and progressed with learning these three levels of chemical thinking, the macro world, sub micro-world and chemical symbolic. The game supported this by offering numerous examples of the chemical categories molecule and atom. Three specific kinds of atom - carbon, hydrogen and oxygen were shown as atomic chemical symbols $(\mathrm{C}, \mathrm{H}, \mathrm{O})$ in molecules represented in chemical formulae $\left(\mathrm{O}_{2}, \mathrm{CO}_{2}, \mathrm{H}_{2} \mathrm{O}, \mathrm{CH}_{4}\right.$ etc) and with $3 \mathrm{~d}$ images of molecular structures that moved around in space. Alongside the molecular and symbolic level offerings was a commentary about the properties and uses of the substances on the macroscopic level (water, carbon dioxide, methane, sugar). Importantly, the analysis presented here shows the participants were highly engaged, as evidenced in their attention to the game, and in the interviewer's role declining as the game came with 
practice to provide all the learning supports needed. This research supports the notion that young children can be positively positioned to begin 'putting on molecular spectacles' [6] earlier than currently expressed in curriculum documents [5]

The Molecularium 'Build' game uses a metaphor of 'building' to show how atoms are the building blocks of molecules. The game players construct specified molecules with particular names and chemical formulae. That the participants were not building physically, molecules in actuality, was not a problem and was clearly obvious to all the study participants. Accepting the idea that representations create the world rather than reflect it the question arises, what other 'new' worlds might be available to young children through the use of ICT visualisations, beyond that of the particulate nature of matter that was afforded by playing with the Molecularium.

Implications. Our findings support the notion that re-positioning children with currently available ICT visualization tools, such as described here with The Molecularium site, can and will change the 'teachability' and 'learnability' of 'concepts' for learners. They can be positively positioned with suitable material and social supports. We call for the specific reconsideration of the current agreements about beginning chemistry curriculum designs, which currently only offer molecular and symbolic levels of thinking in secondary years. We propose that what young children can do and know, about the particulate nature of matter and other big ideas of science, needs to be revisited in light of what new multimedia and ICT representations, visualisations and simulations can offer to young children today.

In this research, knowledge offering of and meaning-making with the three levels of chemical thinking, was readily achieved with the well-designed interactive that provides multiple examples of categories and kinds of particles in an engaging game format that was designed for use of young children. The Nanolab Build game structures the experience of learning symbolic and molecular level signs and concepts, by stepping beginners and early novices through experiences with a range of examples in a game-like multimodal and interactive format. When thus positively positioned with the ideas of atoms and molecules and their chemical symbols, in words and images, the very idea can become available for young children to begin appropriating and making use of as tools for their thinking. That they can make use of the thinking tools in their meaning-making activity is shown in the scientifically appropriate questions asked while playing. Rather than the three levels of chemistry being thought of as too abstract for young children and particle ideas being the problem [5] chemical educators would do well to acknowledge that current visualisations are changing 'learnability' and can support more scientifically accurate and more sophisticated chemical thinking at a younger age than occurs in current practices. One of the benefits of an earlier introduction would be a decrease in conceptual load seen in senior secondary chemistry, by giving learners more time to appropriate the ideas and develop more habitual and expert uses of and with all three levels of chemical thinking.

When positively positioned with 'the idea' the ground is prepared, affording young children's learning experiences that constrain thinking towards more habitual use of scientifically sophisticated 'ways of seeing and doing'.

Acknowledgments. The authors would like to thank the child participants for their willingness to contribute to the research and the anonymous reviewers who contributed greatly to the refinement of the final version of this paper. 


\section{References}

1. Noss, R. Learning the unlearnable: Teaching the unteachable. Dean's Lecture Series 2012; Available from:

http://education.unimelb.edu.au/news_and_activities/events/deans_lecture_series/richard_ noss.

2. Gibson, J.J., The ecological approach to visual perception. 1979, Boston: Houghton Mifflin.

3. Smetana, L.K. and R.L. Bell, Computer simulations to support science instruction and learning: A critical review of the literature. International Journal of Science Education 2012. 34(9): p. 1337-1370.

4. Wilkerson-Jerde, M.H., B.E. Gravel, and C.A. Macrander, Exploring shifts in middle school learners' modeling sctivity while generating drawings, animations, and computational simulations of molecular diffusion. Journal of Science Education and Technology, 2015. 24(2-3): p. 396-415.

5. Skamp, K., Teaching chemistry in primary science: What does the research suggest? . Teaching Science, 2011. 57(4): p. 37-43.

6. Kind, V., Beyond appearances: Students' misconceptions about basic chemical ideas 2004: London.

7. Turkle, S. and S. Papert, Epistemological pluralism and the revaluation of the concrete., in (Eds.) Constructionism. , I. Harel and S. Papert, Editors. 1991, Ablex Publishing Corporation.: Norwood NJ. p. 161-192.

8. Alexander, J.M., K.E. Johnson, and K. Kelley, Longitudinal analysis of the relations between opportunities to learn about science and the development of interests related to science. Science Education, 2012. 96(5): p. 763-786.

9. Siegal, M., Marvelous minds: The discovery of what children know. 2008, Oxford: Oxford University Press.

10. The Molecularium project. 2004; Available from: http://www.molecularium.com/kidsite.html.

11. Howie, D., Preparing for positive positioning, in Positioning theory, R. Harré and L. van. Langenhove, Editors. 1999, Blackwell: Oxford. p. 53-59.

12. Gauvain, M., Cultural tools, social interaction and the development of thinking. Human Development, 2001. 44(2/3): p. 126-143.

13. Jakab, C., Molecules as tools: Discourse, artefacts and children's meaning-making about particles of matter. 2013, The University of melbourne: Melbourne.

14. Leach, J. and P. Scott, Designing and evaluating science teaching sequences: an approach drawing upon the concept of learning demand and a social constructivist perspective on learning. Studies in Science Education, 2002. 38: p. 115-142.

15. Harré, R. and L.van Langenhove, eds. Positioning theory : Moral contexts of intentional action. 1999: Oxford: Blackwell.

16. Jakab, C., Talk about small: Conversations with young children at play with molecule simulations, in Successful science education practices: Exploring what, why and how they worked, C. Redman, Editor. 2013, NOVA Publishers. p. 71-92. 